\title{
National Wilms' Tumor Study Group
}

National Cancer Institute

\section{Source}

National Cancer Institute. National Wilms' Tumor Study Group. NCI Thesaurus. Code C19760.

A group established in 1969 with goals: to improve the survival of children with Wilms tumor and other renal tumors, to study the long-term outcome of children treated successfully by identifying adverse effects of treatment, to study the epidemiology and biology of Wilms tumor and to make information regarding successful treatment strategies for Wilms tumor available to physicians around the world. In 2001 NWTSG was merged into the Children's Oncology Group. Patient entry into NWTSG clinical trial protocols was completed in 2002. 